nature

biotechnology

\section{Playing catch-up}

A new report from the PEW Initiative on Food and Biotechnology suggests that US regulators need to generate more rules, guidelines and perhaps even legislation to meet the challenges of assessing the health, safety and environmental impacts of the next generation of transgenic animals and plants. But given the nature and magnitude of the risks posed by these biotech products, does the system really need an overhaul?

Since 1986, the United States has tenaciously stuck to the principle that assessment of the health, safety and environmental impact of biotech products should require no special laws or regulatory oversight. Under the Coordinated Framework, products manufactured recombinantly receive - in theory at least - the same regulatory treatment as products manufactured by more 'conventional' means. The US Food and Drug Administration (FDA), the Department of Agriculture (USDA) and the Environmental Protection Agency (EPA) evaluate and define biotech products in several ways: under the Food, Drug and Cosmetic Act, the FDA considers them either 'generally recognized as safe (GRAS)' or 'new animal drugs (NADA)'; under the Plant Protection Act and the Federal Insecticide, Fungicide and Rodenticide Act, the USDA and EPA consider them 'plant pests,' 'pesticides produced in plants' or 'noxious weeds'; and under the Toxic Substances Control Act, the EPA considers them 'non-pesticidal chemical substances'.

For the past 18 years since the framework was established, the world has had two Iraq wars, the fall of the Iron curtain, and the United States has had four Presidents (including two George Bushes) and September $11^{\text {th }} 2001$. Biotech has been through five cycles of funding highs and lows. Some of these events changed the world, or at least our perceptions of it. What has changed then about biotech that could justify a new approach to regulation in the US?

The main change of course is the nature of some of the production systems. For instance, transgenic corn can now double as a drug, transgenic salmon can pump out hormones to grow all year round, transgenic silkworms can spin Kevlar instead of silk, and transgenic cows can produce low-methane moos or milk suitable for lactose-intolerant dairy lovers. The question is of course do such systems present a particular challenge to the Coordinated Framework? Clearly, genetically engineered fish or insects represent a threat to their wild relatives, requiring a close assessment of their environmental impact. There would also be no product recalls for transgenic fish, insects or bacteria released into the environment. The genies would be out of the bottle, with the potential to damage human health or the environment. Elsewhere, pharmaceutical crops or animals could enter the human food supply via admixture.

In its most recent report, 'Issues in the Regulation of Genetically Engineered Plants and Animals', PEW discusses the jurisdictional challenges posed to existing regulatory agencies by such types of products (e.g., should the USDA or the FDA regulate a transgenic plant that produces a drug?). The report also delves into the legal authority of the different agencies to regulate these products (e.g., does the FDA's scope cover the environmental impact of a transgenic fish; if so does FDA have sufficient expertise and resources?). In other words, PEW believes not only that there are some rather awkward and potentially obnoxious genies out there, but also that the regulatory stoppers in the bottles are an increasingly bad fit.

The report also highlights inadequacies and incongruence in the existing legislation when applied to new biotech products. For example, the FDA will clearly have to revise guidelines on drug labeling, good laboratory practices, and good manufacturing practices for a plant or animal producing a pharmaceutical compared with a pharmaceutical pill. In this sort of instance, it becomes important to remember that it is implicit in all existing legislation that a clear distinction be made between regulations for the source of a product and regulations for its use. For instance, pig heart valves-from perfectly ordinary non-recombinant porkers-have been used prosthetically in humans for decades. Just because some pig valves are used medically, it doesn't mean the FDA needs to be regulating all pigs in the United States. It's the end product that is important not the means by which it is produced.

Some of the solutions suggested in the PEW report seem less well considered. The idea of using the FDA's NADA provision for all transgenic products goes against one of the US regulatory system's cardinal premises: that regulations should be based on a product's risks, not on the process by which it was made. In several places, the report also suggests the possibility of introducing completely new regulatory structures overseen by single federal agencies that would require the approval of new legislation. Experience has shown that introducing and enacting laws in US Congress is at best unpredictable and at worst unlikely to succeed.

Rather than a complete overhaul, all the US regulatory system requires is an upgrade. And the most important upgrade would be better coordination among the FDA, USDA and EPA. At present, the lack of clarity surrounding agency jurisdiction means that developers of biotech products struggle to understand what data will be required of them, which agency must be contacted and when. One excellent suggestion from the PEW report is that a single lead agency should be assigned with responsibility for affirmatively coordinating the reviews conducted by each of the agencies involved-perhaps the USDA for transgenic plants and the FDA's Center for Veterinary Medicine for transgenic animals.

The Coordinated Framework isn't perfect, but its better than many other regulatory systems around the world. If the kinks about jurisdiction and agency cooperation can be ironed out, then US regulators can start playing catch up with biotech products. And some products need decisions. Waltham, MA-based Aqua Bounty, for example, has been waiting for an FDA decision on its transgenic salmon since 1996. Let's hope it doesn't have to wait for the $2^{\text {nd }} 10$-year anniversary of the Coordinated Framework to get an answer. 